\title{
Influence of IT-facilitated Knowledge Management on Economic Growth
}

\author{
Yujia Ji \\ School of Business, Beijing Language and Culture University, Beijing 100083, China \\ blcujyj@163.com
}

Keywords: knowledge management capability; economic growth; multilateral research cooperation

\begin{abstract}
The development and disperse utilization of information technology has improved knowledge management capability and made it essential to production. In this paper, KM capability is introduced into a new endogenous economic growth model based on Romer's model as a key factor. It's proved in the new model that reinforcement of KM capability makes investing in research sector more profitable than before and increases economic growth rate. So, firms, universities and government should continuously invest in those IT that facilitates KM, like knowledge management system, through multilateral cooperation.
\end{abstract}

\section{Introduction}

The digital revolution has brought the society into an information age and thoroughly changed the organization methods of economic activities. Hence, economic growth model need to be remunerated in order to adapt to the high-tech economy and the knowledge-based society.

In the brand-new era, knowledge has been proved overwhelms labor and capital and becomes the pivotal factor of production. And it has gradually been accepted as a fundamental organizational resource that contributes to market leverage and competitive advantage [1-3]. To take advantage of this vital resource, organizations need to transform disperse individual knowledge into organizational knowledge [4]. The ability to exploit those knowledge is firstly called "absorptive capacity" [5]. Later, knowledge management (KM) emerged as a scientific discipline, defined as process of creating, sharing, using and managing the existing knowledge and information of an organization to achieve organizational objectives [6]. A firm's KM capability will be influenced by its internal and external learning environment, and idiosyncrasy of knowledge.

Romer new classical theory of economic growth examines the impact of technological progress on economic growth and proposed knowledge spillover model. Given that knowledge management capability affects firm's performance and economic growth, the modified growth model should take KM capability into account.

There are two major problems with traditional KM methods, ending up contributing to diminishing marginal return of private firms' investment in knowledge as it's suggested in Romer model.

First, suggested by Cohen and Levinthal, trade-off between effective communication and information assimilation is inevitable within the firm. To communicate efficiently, shared knowledge background is required for expertise in the firm. The consistency of expertise will impede information assimilation between different departments and impairs cross functional interface when their works are highly specialized. In such case, the experiences obtained through "learning-by-doing" in the manufacturing sector can hardly be shared within the entire firm without being translated into lessprofessional legible version. Taking this difficulty into account, a proper level of knowledge overlap between different departments' expertise is necessary though it is less productive. 
Secondly, the existence of intermediary reduces transmission efficiency of external knowledge. In traditional condition, there is a "gate keeper" who is in charge of discovering and converting external knowledge into worthwhile explicit information that can directly applied in research sector, given that the external knowledge such as fundamental scientific achievements are relevant to the firm's research but not customized [7]. In order to fulfill the obligations, the "gate keeper" must be sensitive to the useful knowledge himself and have substantial valuable relationships (most of them are personal). The low level of gatekeeping proficiency transparently degrades a firm's KM capability.

However, with the ubiquitous use of IT in the business world, information technology turns out to be a convenient instrument to assist KM process. It plays different roles to solve the trade-off problem in the firms take different strategies. KM is principally about constructing a system to attain competitive advantage core competencies, involving practice of two strategies: (push) codification and (pull) personalization [8]. The KMS functions as a mechanism that records, shares, and develop knowledge. This makes it easier to extract knowledge from the person who developed it and employ them for various purposes. In manner of speaking, IT enhances KM capability by providing feasible solutions to the two problems in three ways:

1. For those who apply codification strategy, individuals encode their knowledge into a shared knowledge repository, as well as retrieving knowledge others provided. Those stored knowledge forms an asset that can be reused without variable costs. Database Management System will be supportive to such firms, as it functions as a digital storage of explicit knowledge, especially intellectual capital (including patent, trade secret, etc.). The implicit experiences abstracted from manufacturing process can also be converted into explicit knowledge and saved after codification and displayed lucidly in charts, diagrams or data sets. Expertise in research sector or external institutes no longer need to visit manufacturing sector in person or learn the procedures by themselves. The common "time lags" will be curtailed [9]. The workers also save their efforts to summarize and teach experiences repeatedly. All the detailed information can be send to them after DMS's collection and selection as long as they tap in their request. The necessity of knowledge overlap and difficulty to combine outside knowledge sources decline while productivity ascents.

2. Firms that rely on interaction between people and attach great importance to the implicit knowledge often adopt personalization strategy. Information Communication Technology facilitates transfer and sharing of both explicit and tacit knowledge by offering external knowledge to the firms and aiding socialization as well as collaboration between people, which reduces redundant learning efforts. "Knowledge is shared not only face-to-face but also over the telephone, by e-mail, and via videoconferences" to construct a personnel network. Expertise the can catch up with the former research results by learning the digital communication records.

3. As regards the second problem, with combination of ICT and data mining methods, an algorithm specialized in searching and analyzing can share the responsibility of the "gate keeper" and make an improvement. Selection and data mining turns the whole database, made of both internal and external knowledge, to useful resources through offering precisely the knowledge needed in firms' R\&D activities. It can tell from the data trail of customers and products that customers analysis and data of product life cycle, which is crucial to innovation. It also can spot the emerging valuable basic research by scanning relevant articles, news and conference records. The suitable knowledge, recombined and came into use under the Expert System, assists the teamwork among the expertise. Together with Case based Reasoning (supported by Artificial Neural Network), data mining can also turn a person who has limited professional skills into an expert by posing a solution. ANN excels at classifying cases into categories and learn to accomplish tasks by studying examples, generally 
without task-specific programming. Given a specific task and a class of functions F, ANN can learn to use a set of observations to find $\mathrm{F}$ which solves the task in some optimal sense. Along with the KMS, conventional gate keeper's function can be complemented.

Therefore, enhanced by IT support, KM capability become progressively important, and profoundly change the economic growth model. This paper aims to elaborate the changes ITgrounded knowledge management has brought by modifying Romer's model and make suggestions to firms and policy making.

\section{Model}

There are four basic inputs in the model: capital(K), physical labor $(\mathrm{L})$, human capital(H), level of technology(A). Components of knowledge are separated into rival $\mathrm{H}$ and non-rival A. Accordingly, economy has 3 sectors: research sector that use $H_{A}$ and existing stock of knowledge, intermediategoods sector that make use of research sector's design and final goods sector that employs $\mathrm{L}, H_{Y}$ and producer durable.

$$
H=H_{Y}+H_{A}
$$

In the model, $\mathrm{H}$ and $\mathrm{L}$ are fixed, accumulation of $\mathrm{K}$ is determined by the total output and aggregate consumption as cumulative forgone output.

$\dot{K}=Y(t)-C(t)$

Romer assumes "people engaged in research has free access to all the knowledge", so new design created in research sector not only increases the total stock of knowledge but also the productivity of $\mathrm{H}_{\mathrm{A}}$. Other inventors can take advantage of the design by learning its application as well. Technological accumulation simply equals to:

$$
\dot{A}=\delta H_{A} A
$$

However, in the real world, it's impossible to get free access to knowledge. Many kinds of efforts are required to get approach to knowledge. Based on earlier studies, for individuals, the psychological and physical effort is measured by the ease of using an information source called "accessibility". An article is considered of low accessibility because it is challenging to comprehend, retrieve on the Web, or be displayed lucidly. For a productive firm, the accessibility of knowledge matters as well as the specification of knowledge (whether it fits firm's special needs). Knowledge management is an efficient way to promote the accessibility and level of specification of knowledge. It aids knowledge sharing which makes knowledge easier to be found, converts obscure knowledge into intuitive forms and select useful knowledge according to research sector's demand. According to the SECI model, higher KM capability represents more efficient combination and internalization of patented new design (which belongs to explicit knowledge). So to what extent other inventors can make a good use of the new design depends on its own KM capability.

So Romer's assumption should be altered to "exploit rate of the stock of knowledge by people engaged in research is determined by their knowledge management capability and, represented by $m$ $(0 \leq m \leq 1)$ ". Larger $m$ means higher exploit rate. $m$ will be small when the firm is in an environment that is difficult for it to learn or the knowledge it needs is indiscernible.

Hence, in this paper, the equation is adjusted by adding factor $m$ in. 


$$
\dot{A}=\delta m H_{A} A
$$

Therefore, wage of human capital in the research sector $\mathrm{w}_{\mathrm{H}}$ equals to marginal product per capita multiply its price $\mathrm{P}_{\mathrm{A}}$ :

$$
w_{H}=P_{A} \delta m A
$$

Final output $\mathrm{Y}$ in the model is expressed as a function of $\mathrm{L}, \mathrm{H}_{\mathrm{Y}}$ and physical capital input. With the assumption that different types of $\mathrm{K}$ are not perfect substitutes, the function follows the extension of the Cobb-Douglas production function:

$$
Y\left(H_{Y}, L, x\right)=\sum_{i=1}^{\infty} H_{Y}^{\propto} L^{\beta} x^{1-\alpha-\beta}
$$

Moreover, ${ }^{i}$ for different types of goods are taken as continuous variables, the overall output (aggregate demand) of durables follows the production function below:

$$
Y\left(H_{Y}, L, x\right)=\mathrm{H}_{\gamma}^{\alpha} \mathrm{L}^{\beta} \int_{0}^{\infty} x(i)^{1-\alpha-\beta} d i
$$

$\mathrm{x}(i)$ is the units of production that firm which already exposed to fixed-cost investment chooses to maximize its profit for each durable. Differentiating under the integral sign leads to an inverse demand function. Producers take the demand curve in equation (8) as given when setting their profitmaximizing price $\mathrm{p}(\mathrm{i})$.

$$
\begin{aligned}
& p(i)=(1-\alpha-\beta) H_{Y}^{\alpha} L^{\beta} x(i)^{1-\alpha-\beta} \\
& \pi=\max _{x}(1-\alpha-\beta) H_{Y}^{\alpha} L^{\beta} x^{1-\alpha-\beta}-r \eta x
\end{aligned}
$$

$\eta$ is productivity index. $r$ is interest rate. $\pi$ represents firms maximized net revenue (the difference between maximized gross revenue and variable cost).

Based on the principle that excess of revenue over marginal cost must be adequate to cover the interest cost on the initial investment, $\mathrm{P}_{\mathrm{A}}$ is determined in equation (10).

$$
\pi(t)=r(t) P_{A}
$$

The evolution of A is determined by the allocation of resources between a research sector and a final-good sector as well as firm's knowledge management capability. A decides the range of durables that can be produced. In equilibrium, all the durable goods are supplied at $\overline{\mathrm{x}}$ level. So $\mathrm{K}$ and $\mathrm{A}$ is related as equation (11) shows.

$$
K=\eta(m A) \bar{x}
$$

Then Y can be transcribed as:

$$
\begin{aligned}
& Y\left(H_{Y}, L, x\right)=H_{Y}^{\alpha} L^{\beta} \int_{0}^{\infty} x(i)^{1-\alpha-\beta} d i \\
& =\left(H_{Y} A\right)^{\alpha}(L A)^{\beta}(K)^{1-\alpha-\beta} \eta^{\alpha+\beta-1} m^{\alpha+\beta-1}
\end{aligned}
$$

This expression makes nonconvexity of the function palpable. Knowledge spillover effect and 
price setting both matters in the growth model. Small m (poor KM capability) can stockade the spread of knowledge by impeding its transfer and sharing.

Research sector's wage is shown in equation (5). Output sector's wage is measured by its marginal product. The wages paid to human capital in the sectors should be the same.

$$
\begin{aligned}
& w_{H}=P_{A} \delta m A=\alpha H_{Y}^{\alpha-1} L^{\beta} \int_{0}^{\infty} x^{1-\alpha-\beta} d i \\
& H_{Y}=\frac{1 \quad \alpha}{\delta m(1-\alpha-\beta)(\alpha+\beta)} r
\end{aligned}
$$

Common growth rate for all the variables are equal.

$$
\begin{aligned}
& g=\frac{\dot{C}}{C}=\frac{\dot{K}}{K}=\frac{\dot{A}}{A}=\delta m H_{A}=m \delta H-\frac{\alpha}{(1-\alpha-\beta)(\alpha+\beta)} r \\
& \Lambda=\frac{\propto}{(1-\alpha-\beta)(\alpha+\beta)} \\
& g=\frac{\dot{C}}{C}=\frac{r-\rho}{\sigma}
\end{aligned}
$$

Combine (13) and (15) together, $g$ can be expressed as:

$$
g=\frac{m \delta H-\Lambda r}{\sigma \Lambda+1}
$$

\section{Result}

In equation (13'), there is a negative correlation between $\mathrm{m}$ and $\mathrm{H}_{\mathrm{Y}}$. Increase of $\mathrm{KM}$ capability, represented by $\mathrm{m}$ in equation (13'), leads to higher utilization of $\mathrm{A}$ and greater amount of knowledge output in accordance with equation (4), which results in higher productive rate in research sector. Equation (5) indicates the sector produces more output pays temporary higher wage, so it attracts more human capital. Therefore, $\mathrm{K}$ and $\mathrm{H}$ will move into research sector, $\mathrm{H}_{\mathrm{Y}}$ decrease.

Interest rate $\mathrm{r}$ is germane to $\mathrm{H}_{\mathrm{Y}}$ as well. Considering the opportunity cost of human capital is wage income in the manufacturing sector which can be earned immediately and the return of research investment comes in the future, the higher interest rate the lower the net revenue originated from research investment. Hence, with high interest rate, firms lean to invest in manufacturing sector, $\mathrm{H}_{\mathrm{Y}}$ increase.

As it demonstrates in equation (17), increases in $\mathrm{m}$ and $\mathrm{H}$ take different path to speed up growth rate. When single firm take the stock of knowledge as a fixed amount, their ways to improve research sector's performance will be hiring more experts (increase $\mathrm{H}_{\mathrm{A}}$ ) or promote internal KM capability. A permanent increase in $\mathrm{H}$ leads to an increase in $\frac{\mathrm{A}}{\mathrm{K}}$ and $\mathrm{H}_{\mathrm{A}}$. Growth rate increases consequently according to equation (14). But it will be unprofitable to simply increase input of researchers when the knowledge can't be use efficiently under firm's existing framework, which may because of the lack of collaboration that requires repeat study in different phase of the invention. So, the increase of $\mathrm{m}$, when $\mathrm{H}_{\mathrm{A}}$ and $\mathrm{A}$ hold still, improve the growth rate by promoting the exploit rate of knowledge

Equation (17) also illustrates the interest rate $r$ is negatively related with economic growth rate 
g. A decline of interest rate reduces the initial cost of input and stimulates investment in research sector as well as manufacturing sector. Given that research sector experiences an increasing return, $g$ augments correspondingly.

\section{Conclusion}

Currently, overall level of economic growth upsurges because total stock of A increases and KM capability promotes.

As time pass, total accumulation of knowledge increases, with the creation of new knowledge, discovery of previous knowledge by reviewing previous opinions and endow them with fresh implication.

Beyond that, abundant investment in technology creates affluent inventions and boosts the overall knowledge stock $A$ because of "path dependence" stimulation and excessive return. Devoting in research will increase firms' KM capability as well as their total stock of knowledge and in turn fasten accumulation in next round. Those didn't invest primarily will find it harder to involve afterwards with poor initial knowledge stock and be "locked out" in the budding research fields. In some industries, threshold investment is required if a firm want to join in the competition. To avoid missing opportunities and its costs, firms will choose to invest in technology in the inception phase. Return on IT investment excess return on ordinary labor and capital investment [10]. The firms with higher level of IT investment have both higher measured productivity and market value and better future performance potential $[11,12]$.

The omnipresent adoption of IT achievements makes it easier to learn and enhances the knowledge management capability $m$ as well. The higher the KM capability, the more firms will lean to grab the new opportunities proactively because they are confident in successfully exploiting the opportunities and getting adequate payback subsequently.

Seeing how conducive investing in research sector to economic growth, "the overall level of human capital and its segment that devoted to research are higher now than the past", as Romer pointed out in his paper [13]. Therefore, investment in research sector and IT based knowledge management should be encouraged constantly.

Although there is plenty investment in IT, the development of IT based strategic KMS is still undercompensated because only few colossal firms are willing to invest all by themselves.

Develop a system that connects and supports an entire firm requires considerable detailed works. KMS should be designed according to the firm's characteristics. Firms apply codification strategy put KMS's emphasis on storage and retrieval of knowledge. While firms applied personalization strategy use KMS to facilitates communication. For a small firm with few employees, codification of implicit knowledge takes more efforts than assimilate them by teaching. Comparing with mass investment, the profit created by building system will be modicum if discount is taken into consideration, not to mention the possible revenue generated from manufacturing sector if allocating the same resources to production. Also, the evolution of KMS needs considerable feedbacks which is easier to get within a large firm than several small firms. KMS should be adjusted along with changes happened inside and outside the firm. Errors and drawbacks of the system can only be found and corrected after wide-scale use.

Although other than using KMS by themselves firms can sell it for profits, the fact that each KMS should be amended according to its buyer's traits which increases its development cost makes it hard to sell. This make earning profit by selling KMS instead of using it not worthwhile, considering, also, supplementary after-sale services should be promised as well. Hence, firms will not invest heavily in developing KMS if they only want to sell it as a product. 
A practicable way out is to propel the development of KMS mutually by a group of entities.

As stated in the former of this paper, IT can promote KM by facilitating the cooperation between firms and external resources. In fact, firms are testified to increasingly engage in "open innovation" and gradually get used to the non-linear, interactive and multi-agent innovation relationship [14-17]. Apart from traditional explicit patent authorization, universities have already started to exchanged and mutually produced implicit knowledge with firms, which makes co-development of KMS feasible [18]. Each of them engages in a specialized phase: firms jointly invest in KMS development programs and provide their data; universities conduct Industry-funding researches concerning KMS, involving combination of fundamental technologies as well as analyzing specific needs of firms of different types; consulting institutes specialize in collecting primary data and feedbacks from vary firms, generating reports and transferring them to researchers.

Since inter-organizational relationships of such a high involvement regarding innovation are often based on joint or cooperative research ventures, contract research, consulting and social relationships between individuals, government should facilitate the inter-organizational cooperation by creating a friendly environment and basic infrastructure for inter-organizational joint research [19]. For example, government can establish platforms that encourage joint research and contract research. Other than intellectual properties, ongoing researches and firms' demand should also be recorded and displayed on the platform. They will be match by a designed algorithm (simple ATs) and relevant entities will be notified thereafter. Algorithmic traders have been proved effective in the market for liquidity and other fields [20]. Ways to contact the registered parties are only exposed to background managers. Potential suppliers can contact purchasers, discuss for further cooperation after being informed.

\section{References}

[1] Drucker P F. Concept of the Corporation[M]. transaction Publishers, 1993.

[2] Nonaka I, Takeuchi H. The knowledge-creating company: How Japanese companies create the dynamics of innovation[M]. Oxford university press, 1995.

[3] Leonard-Barton D. Wellsprings of knowledge: Building and sustaining the sources of innovation[J]. 1995.

[4] Egbu C O. Knowledge management in construction SMEs: coping with the issues of structure, culture, commitment and motivation[C]//ARCOM Sixteenth Annual Conference. 2000: 8392.

[5] Cohen W M, Levinthal D A. The implications of spillovers for R\&D investment and welfare: a new perspective[J]. Administrative Science Quarterly, 1990, 35(1990): 128-152.

[6] McInerney C. Knowledge management and the dynamic nature of knowledge[J]. Journal of the Association for Information Science and Technology, 2002, 53(12): 1009-1018.

[7] Tushman M L. Special boundary roles in the innovation process[J]. Administrative science quarterly, 1977: 587-605.

[8] Hansen M T, Nohria N, Tierney T. What's your strategy for managing knowledge[J]. The knowledge management yearbook 2000-2001, 1999: 1-10.

[9] Lee D M S, Allen T J. Integrating new technical staff: Implications for acquiring new technology[J]. Management Science, 1982, 28(12): 1405-1420.

[10] Dewan S, Min C. The substitution of information technology for other factors of production: A firm level analysis[J]. Management science, 1997, 43(12): 1660-1675.

[11] Bharadwaj A S, Bharadwaj S G, Konsynski B R. Information technology effects on firm performance as measured by Tobin's q[J]. Management science, 1999, 45(7): 1008-1024. 
[12] Hitt L M, Brynjolfsson E. Information technology, organizational transformation, and business performance[C]//Productivity, inequality, and the digital economy. MIT Press, 2002: 55-91.

[13] Romer P M. Endogenous technological change[J]. Journal of political Economy, 1990, 98(5, Part 2): S71-S102.

[14] Chesbrough H W. Open innovation: The new imperative for creating and profiting from technology[M]. Harvard Business Press, 2006.

[15] Kline S J. Innovation is not a linear process[J]. Research management, 1985, 28(4): 36-45.

[16] Lundvall B A, Dosi G, Freeman C. Innovation as an interactive process: from user-producer interaction to the national system of innovation[J]. 1988, 1988: 349-369.

[17] Von Hippel E. Cooperation between rivals: informal know-how trading[J]. Research policy, 1987, 16(6): 291-302.

[18] Cohen W M, Nelson R R, Walsh J P. Links and impacts: the influence of public research on industrial R\&D[J]. Management science, 2002, 48(1): 1-23.

[19] Perkmann M, Walsh K. University-industry relationships and open innovation: Towards a research agenda[J]. International Journal of Management Reviews, 2007, 9(4): 259-280.

[20] Hendershott T, Riordan R. Algorithmic trading and the market for liquidity[J]. Journal of Financial and Quantitative Analysis, 2013, 48(4): 1001-1024. 